\title{
HPV DNA Testing of the Residual Sample of Liquid- Based Pap Test: Utility as a Quality Assurance Monitor
}

\author{
Rosemary E. Zuna, M.D., William Moore, Ph.D., S. Terence Dunn, Ph.D. \\ Department of Pathology (REZ, STD) and the Native American Prevention Research Center (WM), \\ University of Oklahoma Health Sciences Center, Oklahoma City, Oklahoma
}

HPV DNA testing of the residual sample volume of liquid-based Pap tests has been recommended as a way to determine the appropriate follow-up for women who have equivocal results in routine clinical screening. A major aspect of quality assurance in the cytopathology laboratory consists of correlation of smear interpretation with biopsy or conization results as mandated by CLIA ' 88 . However, the use of histology as the gold standard suffers from similar problems of subjectivity and sampling as the Pap smear. In this study we explore the potential use of HPV DNA testing of the residual volume from the ThinPrep ${ }^{\circledR}$ Pap Test $^{\mathrm{TM}}$ (Cytyc Corporation, Boxborough, Massachusetts) as a substitute gold standard in quality assurance monitoring of a cervical cytology screening program. The residual samples from 397 ThinPrep ${ }^{\circledR}$ Pap cases were retrospectively analyzed for high-risk HPV DNA using the Hybrid Capture II ${ }^{\mathrm{TM}}$ technique. Sensitivity $(\mathbf{7 1 . 8 \%})$, specificity $(\mathbf{8 6 . 5 \%})$, predictive value of positive $(77.1 \%)$ and negative $(82.9 \%)$ ThinPrep ${ }^{\circledR}$ Pap interpretations were calculated on the basis of HPV DNA results for $\mathbf{2 6 6}$ cases classed as either squamous intraepithelial lesion (SIL) or negative. Overall, there was agreement between the two tests in $\mathbf{8 0 . 8 \%}$ of cases (Cohen's kappa = .59). The percentage of HPV DNApositive cases interpreted as atypical squamous cells of uncertain significance (ASCUS) was $43.7 \%$, and the percentage of negative cases was $17.1 \%$. We believe that this approach is an objective adjunct to the traditional quality assurance protocol, with the added benefit that it includes cases interpreted as negative, as well as abnormal cases that do not come to biopsy.

Copyright () 2001 by The United States and Canadian Academy of Pathology, Inc.

VOL. 14, NO. 3, P. 147, 2001 Printed in the U.S.A.

Date of acceptance: October 24, 2000.

This study was presented in part at the United States-Canadian Academy of Pathology 86th Annual Meeting, New Orleans, LA, March 25-31, 2000. Address reprint requests to: Rosemary E. Zuna, M.D., Department of Pathology, BMSB 451, University of Oklahoma Health Sciences Center, Oklahoma City, OK 73190; e-mail: rosemary_zuna@ouhsc.edu; fax: 405-271-6573.
KEY WORDS: Cytology, Human papillomavirus, Pap test, Quality assurance, Screening, Sensitivity, Specificity.

Mod Pathol 2001;14(3):147-151

Emergence of liquid-based Pap tests in clinical screening for the precursors of cervical carcinoma has the potential for revolutionizing the traditional Pap test. Recent clinical series (1-3) have suggested that the ThinPrep ${ }^{\circledR}$ PapTest $^{\mathrm{TM}}$ (Cytyc Corporation, Boxborough, Massachusetts) is more sensitive than the traditional Pap smear for the detection of cervical squamous intraepithelial lesions (SIL). In addition, the ThinPrep ${ }^{\circledR}$ Pap test has the added benefit that a residual sample, especially in problematic cases, can be used to test for human papillomavirus (HPV) DNA using the Hybrid Capture II technique (4). Because of the high correlation of HPV results (using high-risk HPV probes) with SIL (5-7), the results of this test can be used to direct the follow-up of women with ASCUS (atypical squamous cells of uncertain significance) Pap results $(5,8)$. This report describes our experience with the use of the HPV test as a quality assurance monitor for cytologic interpretation. Use of HPV DNA testing in quality assurance monitoring was first suggested by Sherman et al. (9). At present, correlation of cytology and histology is performed using those cases coming to biopsy. Although the current approach certainly gathers substantive information, biopsy correlation is laborious and suffers from similar problems of observer variability $(10,11)$ and sampling error (11) as cytologic interpretation. In some cases, colposcopic biopsies can be falsely negative, which significantly complicates the correlation process. Furthermore, tissue studies are only performed on a subset of patients, that is, those with abnormal results who return for follow-up in the same institution. This leaves significant gaps in the quality assurance process, particularly involving the incidence of falsely negative cytologic interpretations. Use of this molecular test as an additional monitor can offer a complementary, objective measure of the effectiveness of cyto- 
logic interpretation. This study was undertaken to evaluate the potential for this approach using our clinical cases.

\section{METHODS}

\section{Patient Selection}

This study was approved by the Institutional Review Board of the University of Oklahoma Health Sciences Center. The samples were derived from the ThinPrep ${ }^{\circledR}$ Pap cases submitted for cytologic interpretation to the Cytopathology Laboratory of University Hospital as part of routine patient care. The patient population is predominantly that of a screened, low-risk group. However, there is a tendency for our referring clinicians to offer the ThinPrep ${ }^{\circledR}$ Pap test to patients with a history of abnormal smears, so that the samples included here represent a higher risk subset of the population served. The 397 test cases were unselected patients with a spectrum of cytologic interpretations, including those interpreted as negative for tumor or dysplasia. The diagnoses used are the original results as signed out by one of three rotating pathologists or one of nine cytotechnologists. The cytology personnel were not aware of plans to send samples for HPV DNA analysis, and the molecular pathology laboratory personnel had no access to the cytologic interpretation.

\section{HPV DNA Testing}

The residual PreservCyt (Cytyc Corporation, Boxborough, MA) vial from the test cases was sent to the Molecular Pathology Laboratory for HPV testing. This occurred immediately before routine disposal of the residual sample after the cytologic report was rendered and within 2 weeks of receipt in the laboratory. The HPV DNA test, using the Hybrid Capture II Microplate (HCII) System (Digene Corporation, Beltsville, MD; 12), was performed on cell pellets derived from $4 \mathrm{~mL}$ of residual volumes of PreservCyt.
This chemiluminescent signal-amplified hybridization assay uses an RNA probe cocktail that detects the high-risk HPV types 16, 18, 31, 33, 35, 39, 45, 51, 52, 56, 58, 59, and 68. The cocktail for the low-risk HPV subtypes was not used in this study. The HCII microplate was read on a Dynex MLX luminometer (Dynatech Technologies, Chantilly, VA). For the assay to be valid, positive and negative calibrators must meet set criteria; samples with readings above the mean value of the positive calibrators $(1 \mathrm{pg} / \mathrm{mL})$ are considered to be positive. Test results are considered to be equivocal when their values are below the mean cutoff value of the positive controls by less than $15 \%$. For the purposes of statistical comparison with cytology in this report, equivocal cases were deleted from further analysis.

\section{RESULTS}

The results of the cytologic study and the HPV analysis for the 397 samples tested are shown in Table 1. The HPV DNA results of five cases were equivocal and included four interpreted as negative by cytology and one as ASCUS by cytology. Because of the uncertain significance of this result with respect to the presence or absence of HPV DNA, these cases $(1.3 \%$ in this series) were excluded from further analysis in this study; however, this percentage may be a helpful indicator in monitoring the validity of the test conditions in the laboratory.

The percentage of high-risk HPV DNA-positive cases in the series increased with the severity of the cytologic interpretation, showing a high association with SIL, particularly with diagnoses of high-grade dysplasia. It should be noted that because the subset of low-risk HPV subtypes (i.e., HPV 6, 11, 42, 43, 44) was not included in this study, some lesions associated with these viruses would not be detected in our series. Other studies (5) have indicated that these cases would be few and unlikely to be associated with high-grade squamons intraepithelial lesion.

TABLE 1. Distribution of Cytologic Interpretations of ThinPreps with HPV DNA Analysis of Residual PreservCyt Samples

\begin{tabular}{|c|c|c|c|c|c|}
\hline Cytology & $\mathrm{HPV}+(\%)^{*}$ & $\mathrm{Hpv}-(\%)$ & Total Valid & Equiv† & Total \\
\hline Negative & $29(17.1)$ & $141(82.9)$ & 170 & 4 & 174 \\
\hline ASCUS-all $\ddagger$ & $55(43.7)$ & $71(56.3)$ & 126 & 1 & 127 \\
\hline ASCUS-R & $16(31.4)$ & 35 (68.6) & 51 & 0 & 51 \\
\hline ASCUS-D & $39(52.0)$ & $36(48.0)$ & 75 & 1 & 76 \\
\hline LSIL & $49(70.0)$ & $21(30.0)$ & 70 & 0 & 70 \\
\hline HSIL & $25(96.2) \S$ & $1(3.8)$ & 26 & 0 & 26 \\
\hline Total & $158(40.3)$ & $234(59.7)$ & 392 & 5 & 397 \\
\hline
\end{tabular}

* Percentages in this column determined using Total Valid as the denominator; equivocal cases were not included in this calculation.

$\dagger$ Eqiv = equivocal for HPV DNA; not included in calculated percentages. Total percentage of equivocal cases in this series was $1.3 \%$.

$\ddagger$ ASCUS-R and ASCUS-D refer to ASCUS favor reactive process and ASCUS favor dysplasia, respectively; the sum of these categories is represented in the row ASCUS-All.

$\S$ The percentage of total cases containing HPV DNA is determined by the distribution of cases tested and does not have biological relevance in the absence of a statistical sample of the total population. However, the percentages of the individual cytologic categories should be reproducible for each laboratory given an adequate number of cases. 
laboratory will vary with the population served, the percentage of HPV DNA-positive ASCUS, negative, or SIL cases should ideally fall within a limited range. Significant deviations from consensus values should trigger a reassessment of cytologic criteria within the laboratory. On a case-by-case basis, noncorrelation between the cytologic and HPV results should trigger rescreening of the cytology sample, and a determination should be made as to whether there was a screening/interpretive error using standard cytologic criteria. Unexplained variances should be noted and monitored.

Although clearly involving more objective data than that of visual interpretation, the use of HCII HPV results as the gold standard for cytologic interpretation requires additional validation and clarification. The results in the literature to date are promising. Comparison studies between HCII and PCR-based HPV assays have shown excellent results with agreement of $91.4 \%$ (kappa $=.65$ ) for lowgrade squamons intraepithelial lesions lesions in the ALTS trial (7). Reithmuller et al. (18) found that HCII and PCR identified nearly equivalent prevalences of HPV in cervical smear specimens. Rigorous quality control standards must be in place in the molecular laboratory. In a comparison study between three laboratories using HC I, an earlier version of the current method, Schiffman et al. (19) found strong concordance between interlaboratory correlations and the HPV DNA reference standard as well as with the concurrent cytopathologic diagnoses.

However, there are also ambiguities in data interpretation that remain to be addressed. For example, the clinical significance of the "equivocal" HPV DNA result using the HCII is unclear. Possible causes of these equivocal results are an extremely low copy number of HPV DNA in the cell sample that is beneath the detection threshold for the HCII or undefined variances in the cell samples that generate nondiagnostic, spurious results. When used clinically to determine follow-up of a patient with ThinPrep ${ }^{\circledR}$ Pap interpreted as ASCUS, we currently recommend that a new sample be obtained for retesting from patients with equivocal HPV DNA results.

A second unresolved issue relates to the significance of the cases defined as false-negative cytologic interpretations on the basis of positive HPV DNA results. It is generally accepted that some women test positive for HPV who do not have SIL. Using the HC I method, an earlier version of the current method, Hall et al. (17) found that $35 \%$ of women testing positive for HPV DNA were disease negative, whereas Clavel (6) reported that $8.8 \%$ of women with negative cytologies tested positive for high-risk HPV subtypes. Riethmuller et al. (18) found that $14.3 \%$ of their cases with negative cytol- ogy contained high-risk HPV DNA using the HCII, compared with $25.1 \%$ by PCR. The significance of HPV DNA-positive/cytology-negative cases in our study $(17.1 \%)$ is unclear. Although classified as false-negative cytologies for the purposes of this analysis, these cases may be negative because of a multitude of factors including cytologic undercalls, subclinical HPV infection, relative insensitivity of cytologic detection compared with the HCII, or other, as yet undefined, methodological problems. Occasional sporadic false-positive results have been reported using the earlier HC I test (19). We intend to re-evaluate our cases in this category (as well as the HPV-defined false-positive cases), which will be the subject of a subsequent publication. For quality assurance purposes, such noncorrelating cases (as well as HPV DNA-negative cases with cytologic interpretations of SIL) should be referred to the cytopathology supervisor and the ThinPrep ${ }^{\circledR}$ Pap slides reviewed for diagnostic errors.

In summary, this study illustrates the substantial utility of HPV DNA testing of the residual volume of liquid-based Pap tests in a quality assurance program for the cytopathology laboratory that offers these tests.

Acknowledgment: We gratefully acknowledge the skilled technical assistance of Richard Allen.

\section{REFERENCES}

1. Lee KR, Ashfaq R, Birdsong GG, Corkill ME, McIntosh KM, Inhorn SL. Comparison of conventional Papanicolaou smears and a fluid-based, thin layer system for cervical cancer screening. Obstet Gynecol 1997;90:278-84.

2. Papillo JL, Zarka MA, St John TL. Evaluation of the ThinPrep ${ }^{\circledR}$ Pap test in clinical practice. A seven-month, 16,314case experience in northern Vermont. Acta Cytol 1998;42: 203-8.

3. Guidos BJ, Selvaggi SM. Use of the ThinPrep ${ }^{\circledR}$ Pap Test in clinical practice. Diagn Cytopathol 1999;20:70-3.

4. Manos MM, Kinney WK, Hurley LB, Sherman ME, ShiehNgai J, Kurman RJ, et al. Identifying women with cervical neoplasia: using human papillomavirus DNA testing for equivocal Papanicolaou results. JAMA 1999;281:1605-10.

5. Shiffman M, Herrero R, Hildesheim A, Sherman ME, Bratti M, Wacholder S, et al. HPV DNA testing in cervical cancer screening: results from women in a high-risk province of Costa Rica. JAMA 2000;283:87-93.

6. Clavel C, Bory JP, Rihet S, Masure M, Duval-Binninger I, Putaud I, et al. Comparative analysis of human papillomavirus detection by hybrid capture assay and routine cytologic screening to detect high-grade cervical lesions. Int J Cancer 1998;75:525-8.

7. The ALTS Group. Human papillomavirus testing for triage of women with cytologic evidence of low-grade squamous intraepithelial lesions: baseline data from a randomized trial. J Natl Cancer Inst 2000;92:397-402.

8. Cox T, Lorincz A, Schiffman MH, Sherman ME, Cullen A, Kurman RJ. Human papillomavirus testing by hybrid capture appears to be useful in triaging women with a cytologic diagnosis of atypical squamous cells of undetermined significance. Am J Obstet Gynecol 1995;172:946-54. 
9. Sherman ME, Schiffman MH, Lorincz AT, Manos MM, Scott DR, Kurman RJ, et al. Toward objective quality assurance in cervical cytopathology: correlation of cytopathologic diagnoses with detection of high-risk human papillomavirus types. Am J Clin Pathol 1994;102:182-7.

10. Ismail SM, Colclough AB, Dinnen JS, Eakins D, Evans DM, Gradwell E, et al. Reporting cervical intra-epithelial neoplasia (CIN): intra- and interpathologist variation and factors associated with disagreement. Histopathology 1990;16:371-6.

11. Joste NE, Crum CP, Cibas ES. Cytologic/histologic correlation for quality control in cervicovaginal cytology. Experience with 1582 paired cases. Am J Clin Pathol 1995;103:32-4.

12. Nindl I, Lorincz A, Mielzynska I, Petry U, Baur S, Kirchmayr R, et al. Human papillomavirus detection in cervical intraepithelial neoplasia by the second-generation hybrid-capture microplate test, comparing two different cervical specimen collection methods. Clin Diagn Virol 1998;10:49-56.

13. Lee JJ, Tu ZN. A better confidence interval for kappa in measuring agreement between two raters with binary outcomes. J Comp Stat 1994;3:301-21.

14. Woodhouse SL, Stastny JF, Styer PE, Kennedy M, Praestgaard $\mathrm{AH}$, Davey DD. Interobserver variability in subclassification of squamous intraepithelial lesions: results of the College of American Pathologists Interlaboratory Comparison Program in Cervicovaginal Cytology. Arch Pathol Lab Med 1999;123: 1079-84.

15. Liaw KL, Glass AG, Manos MM, Greer CE, Scott DR, Sherman $\mathrm{M}$, et al. Detection of human papillomavirus DNA in cytologically normal women and subsequent cervical squamous intraepithelial lesions. J Natl Cancer Inst 1999;91:954-60.

16. Clavel C, Masure M, Bory JP, Putaud I, Mangeonjean C, Lorenzato M, et al. Hybrid Capture II-based human papillomavirus detection, a sensitive test to detect in routine highgrade cervical lesions: a preliminary study on 1518 women. Br J Cancer 1999;80:1306-11.

17. Hall S, Lorincz A, Shah F, Sherman ME, Abbas F, Paull G, et al. Human papillomavirus DNA detection in cervical specimens by hybrid capture: correlation with cytologic and histologic diagnoses of squamous intraepithelial lesions of the cervix. Gynecol Oncol 1996;62:353-9.

18. Reithmuller D, Gay C, Bertrand X, Bettinger D, Schaal JP, Carbillet JP, et al. Genital human papillomavirus infection among women recruited for routine cervical cancer screening or for colposcopy determined by Hybrid Capture II and polymerase chain reaction. Diagn Mol Pathol 1999;8:157-64.

19. Schiffman MH, Kiviat NB, Burk RD, Shah KV, Daniel RW, Lewis $\mathrm{R}$, et al. Accuracy and interlaboratory reliability of human papillomavirus DNA testing by hybrid capture. J Clin Microbiol 1995;33:545-50.

\section{Book Review}

\section{Mills SE, Gaffey MJ, Frierson HF Jr: Tumors of the Upper Aerodigestive Tract and Ear, At- las of Tumor Pathology, 455 pp, Washing- ton, DC, Armed Forces Institute of Pathol- ogy, 2000 (\$95.00).}

Even if one were to disregard the price, this would still be my first choice among several pretty good books on ENT tumors that appeared in print recently. I simply do not see how this topic could be covered any better. The only thing that I did not like was the title! ('Upper'-does that mean that there is also a 'lower 'aerodigestive tract? I could not find this term in two of my medical dictionaries, but I'd better stop arguing lest somebody think that I am full of air!)

All the rest is, however, just as one would have expected from a team headed by Dr. Mills. Their approach is extremely methodical and comprehensive. The text flows seamlessly, and it is a pleasure to read-it is not only didactic but also entertaining. Most readers will appreciate the unpretentious but authoritative approach to tumor diagnosis. One cannot help but wonder how much personal experience these authors have condensed into the declarative sentences stockpiled in this book. There is a good balance between important common tumors and less common ones that become important only when you cannot recognize them. Illustrations are excellent, except for a few black and white pictures (taken over from other sources or the previous edition of this atlas) and an occasional gross clinical picture. These are, however, only minor blemishes that should not detract from this excellent book. I mentioned it here to show that I can be critical, and also to let the authors know that I could have lived without a clinical picture of an accessory tragus or branchial cleft cyst in a tumor book.

Atlases are supposed to be visual aids, and their forte lies typically in the illustrations. There is no question that Dr. Mills and his associates have fulfilled this postulate and produced an excellent atlas. I am, however, at a loss in deciding whether the pictures are better than the text or vice versa. If the text is better, would that transform it into a textbook? To understand my dilemma, please buy the book and decide for yourself whether you want to use it as an atlas or a textbook.

Ivan Damjanov

University of Kansas School of Medicine

Kansas City, Kansas 